\title{
Evaluation and Exploration on the Effect of the Management of Chronic Obstructive Pulmonary Disease in Rural Areas through an Internet-Based Network Consulting Room
}

\author{
Yan Yan ${ }^{\mathrm{a}}$ Li Liu $^{\mathrm{b}} \quad$ Jing Zeng ${ }^{\mathrm{c}} \quad$ Liang Zhang $^{\mathrm{a}}$ \\ ${ }^{a}$ School of Medicine and Health Management, Tongji Medical College, Huazhong University of Science and \\ Technology, Wuhan, China; ${ }^{b}$ Tian You Hospital Affiliated to Wuhan University of Science and Technology, Wuhan, \\ China; ' School of Medicine, Wuhan University of Science and Technology, Wuhan, China
}

\section{Significance of the Study}

- The management of patients with chronic obstructive pulmonary disease after discharge through a network consulting room versus the traditional pattern was compared; use of the network consulting room to manage chronic obstructive pulmonary disease patients could effectively improve the quality of life of chronic obstructive pulmonary disease patients and reduce the rehospitalization rate.

\section{Keywords}

Network consulting rooms · Chronic obstructive pulmonary disease $\cdot$ Rural areas

\begin{abstract}
Objective: This study aims to improve the management quality of chronic obstructive pulmonary disease (COPD) in rural areas. Methods: Two hundred forty discharged COPD patients were divided into an intervention group and a control group. In the intervention group, 120 patients established contact with doctors through the network consulting room, i.e., the doctor's mobile platform, and were managed through video, voice, and text by the doctors, kept close contact with the doctors after discharge (education, consultation), and received electronic prescriptions, and drugs were sent to the patients' door by online retailers. The patients in
\end{abstract}

the control group were managed in the traditional manner. One year later, the predicted forced expiratory volume in $1 \mathrm{~s}$ (FEV1)\%, FEV1/forced vital capacity (FVC), and CAT scores and the number of rehospitalized patients were compared between these 2 groups. Results: After 1 year of follow-up, the predicted FEV1\% and the FEV1/FVC ratio were significantly higher in the intervention group than in the control group $(p<0.05)$. CAT scores were lower for patients in the intervention group than for those in the control group after 1 year of follow-up ( $p<0.05$ ). After 1 year of follow-up, 22 $(18.33 \%)$ patients were rehospitalized in the intervention group and 58 (48.33\%) patients were rehospitalized in the control group $(p<0.05)$. Conclusion: Doctors can improve the quality of life of patients with COPD and reduce the number of rehospitalizations through use of the network consulting room.

(c) 2018 The Author(s)

Published by S. Karger AG, Basel

\begin{tabular}{ll}
\hline KARGER & $\begin{array}{l}\text { @ 2018 The Author(s) } \\
\text { Published by S. Karger AG, Basel }\end{array}$ \\
$\begin{array}{l}\text { Openger } \\
\text { E-Mail karger@karger.com }\end{array}$ & $\begin{array}{l}\text { Thisis an Open Access article licensed under the Creative Commons } \\
\text { Attribution-NonCommercial-4.0 International License (CC BY-NC) } \\
\text { (hwtp://www.karger.com/Services/OpenAccessLicense), applicable to } \\
\text { the online version of the article only. Usage and distribution for } \\
\text { commercial purposes requires written permission. }\end{array}$
\end{tabular}

Yan Yan

School of Medicine and Health Management, Tongji Medical College

Huazhong University of Science and Technology, No. 13 of Hangkong Road

Wuhan 430000 (China)

E-Mail yanyantjmu@163.com 


\section{Introduction}

In recent years, the prevalence of chronic diseases has increased rapidly in rural areas of China [1]. Due to their high incidence, low awareness, low control rate and heavy economic burden [2], the control and management of chronic diseases have many deficiencies [3]. Therefore, the Chinese government has issued a series of policies, hoping to improve the management of chronic diseases by encouraging medical staff in public hospitals, including retired professionals, to work full-time and part-time, sharing technological resources to improve the shortage of professionals in the medical field [4]. The 7LKCOM Internet Hospital has online data systems, including an electronic health record system, an electronic medical record system, an electronic prescription and online order system, a remote diagnosis and treatment system, a prescription audit and drug delivery system, and a payment and settlement system. It established network consulting rooms for doctors, leading to the advent of a new model of medical service [5]. Chronic obstructive pulmonary disease (COPD) is the most common cause of continuous hospitalization in rural areas. This study was undertaken to compare network consulting rooms with the traditional system of management of COPD.

\section{Materials and Methods}

\section{General Information}

A total of 240 hospitalized COPD patients (168 males and $72 \mathrm{fe}$ males) who visited the Nosocomial Infection Department and the Respiratory Department of a hospital in Wuhan from February 2014 to February 2015 were enrolled into this study. The age of these patients ranged from 40 to 75 years, and the average age was $65.41 \pm$ 1.02 years. The majority of these patients $(n=212 ; 88.67 \%)$ had a history of smoking. The course of the disease ranged between 12 and 30 years, with an average of $21 \pm 1.80$ years. These 240 patients had different degrees of cough, expectoration, and dyspnea. A pulmonary function test revealed that, after inhalation of a bronchodilator, the forced expiratory volume in $1 \mathrm{~s}$ (FEV1)/forced vital capacity (FVC)\% was $<70 \%$, which met the diagnostic criteria for COPD [6].

\section{Management Methods}

The 240 COPD patients were randomly divided into 2 groups, i.e., a control group and an intervention group. The gender, age, and other characteristics of the 2 groups of patients are shown in Table 1; the differences in demographic characteristics were not statistically significant $(p>0.05)$.

For the control group, the traditional management mode was adopted; oral and written medical advice at discharge focused on diet, exercise, and medication again. Patients were followed up by phone after discharge (including postdischarge symptom assessment, medication, improvement of their living ability, and reminders regarding reexamination).
In the intervention group, the doctor introduced the patient's information in his or her network consulting room before the patient was discharged, and continued to carry out the management of patient after discharge from hospital through the network consulting room. Educational information, with pictures and texts that could easily be understood by patients was sent to patients in a mass manner. After discharge from the hospital, these patients could consult the doctors at any time via text, voice, picture, and video. All doctors were familiar with the patient's diagnosis and treatment. They provide individualized and accurate service for patients. If a patient was found to have signs of aggravation, the doctor immediately adjusted the medication (escalation of or decrease in drugs and discontinuation or addition of antibiotics) and prepared beds for patients who needed hospitalization.

An Internet hospital can send drugs to the patient according to the prescription of the network doctor. The network doctor inputs each patient's diagnosis, results of pulmonary function tests, and medications in order to facilitate evaluation of the patient's condition after discharge, individually answer the patient's questions, and remind patients to undergo a reexamination. These two groups of patients were followed up for 1 year.

\section{Evaluation Indexes}

Pulmonary Function Test

The FEV1/FVC ratio and the predicted FEV1\% value were measured upon discharge and 1 year after discharge.

\section{COPD Assessment Test [7]}

The COPD assessment test (CAT) questionnaire includes 8 items. Each item scores $0-5$ points according to the degree of influence as follows: $0-10$ points, "slight influence;" 11-20 points, "moderate influence;" 21-30 points, "severe influence;" and 31-40 points, "very severe influence." The score range is $0-40$ points.

\section{Statistical Analysis}

The data were statistically analyzed using statistical software SPSS 20.0. Continuous data were expressed as means \pm SD, and comparisons between the 2 groups were made using the $t$ test. Discreet data were compared using the $\chi^{2}$ test. $p<0.05$ was considered statistically significant.

\section{Results}

\section{Comparison of Lung Function Indexes between the} Two Groups of Patients with COPD

The differences in predicted FEV1\% values and FEV1/ FVC ratios upon discharge between these 2 groups were not statistically significant (respectively; $p>0.05$ for both). The differences in predicted FEV1\% values and FEV1/FVC ratios 1 year after discharge between these 2 groups were statistically significant (respectively; $p<0.05$ for both). Pulmonary function was significantly improved after 1 year of intervention by a doctor through the network consulting room for COPD patients after discharge compared to the control group (Table 2). 
Table 1. Comparison of demographic factors between the 2 groups of patients

\begin{tabular}{|c|c|c|c|}
\hline Demographic factors & $\begin{array}{l}\text { Intervention group } \\
(n=120)\end{array}$ & $\begin{array}{l}\text { Control group } \\
(n=120)\end{array}$ & $p$ value \\
\hline Age, years & $65.42 \pm 0.62$ & $64.65 \pm 0.88$ & 0.832 \\
\hline Gender (male/female) & $72 / 48$ & $80 / 40$ & 0.687 \\
\hline \multicolumn{4}{|l|}{ Degree of education (primary school/junior high } \\
\hline school/higher than junior high school) & $42 / 46 / 32$ & $46 / 40 / 34$ & 0.725 \\
\hline Current smokers or previous smokers, $n(\%)$ & $108(90.00)$ & $104(86.67)$ & 0.516 \\
\hline Duration of the disease, years & $16.50 \pm 4.32$ & $15.90 \pm 5.02$ & 0.771 \\
\hline \multicolumn{4}{|l|}{ COPD severity classification stage } \\
\hline (0/I/II/III/IV) & $12 / 27 / 67 / 14$ & $10 / 25 / 70 / 15$ & 0.692 \\
\hline
\end{tabular}

Table 2. Comparison of pulmonary function between the 2 groups of patients before and after discharge

\begin{tabular}{llll}
\hline & Intervention time & FEV1\% predictive value & FEV1/FVC \\
\hline Intervention group $(n=120)$ & Discharge & $40.98 \pm 9.86$ & $54.08 \pm 6.38$ \\
& One year after discharge & $62.94 \pm 10.12^{\mathrm{a}}$ & $65.36 \pm 5.85^{\mathrm{a}}$ \\
$p$ value & & 0.012 & 0.013 \\
\hline Control group $(n=120)$ & Discharge & $41.08 \pm 9.27$ & $53.47 \pm 6.62$ \\
& One year after discharge & $47.87 \pm 4.68^{\mathrm{a}}$ & $59.71 \pm 4.28^{\mathrm{a}}$ \\
& & 0.024 & 0.027 \\
\hline
\end{tabular}

FEV1, forced expiratory volume in $1 \mathrm{~s}$; FVC, forced vital capacity. ${ }^{\text {a }}$ Compared with the same group at discharge $(p<0.05)$; the FEV1\% and FEV1/FVC of the 2 groups were improved after 1 year of follow-up $(p<0.05)$.

\section{CAT Scores of Patients with COPD}

After 1 year of follow-up the CAT scores in these 2 groups decreased, and the differences were statistically significant when compared with the scores at discharge $(p<0.05$ for both; Table 3). After 1 year of follow-up, the CAT scores were lower in the intervention group than in the control group, and the difference was statistically significant $(p<0.05)$.

\section{Condition of the Patients}

A comparison of patients with $\geq 2$ hospitalizations per year due to an acute exacerbation is shown in Table 4 . In the intervention group, 22 patients (18.33\%) had $\geq 2$ hospitalizations per year due to an acute exacerbation within 1 year, while in the control group 58 patients (48.33\%) had $\geq 2$ hospitalizations per year due to an acute exacerbation within 1 year. The number of patients who required continuous hospitalization due to exacerbation was significantly lower in the intervention group than in the control group $(p<0.05)$.

Network Consulting Rooms for the Management of COPD in Rural Areas
The number of CPOD patients with continuous hospitalization due to an acute exacerbation was significantly greater in the control group than in the intervention group (Table 4).

\section{Discussion}

COPD is a preventable and treatable disease characterized by an airflow limitation [8]; its prevalence ranks second in patients with continuous hospitalization in rural areas [9], and its fatality ranks first among respiratory system diseases [10]. Continuous management of COPD patients after discharge is very important [11]. Correct drug treatment can relieve the symptoms of COPD patients [12] and reduce the risk and frequency of acute attacks [13]. Furthermore, it can improve the health and exercise tolerance of patients [14]. Traditional modes of managing chronic diseases have disadvantages such as inconveniences, fragmentation, and poor communication. Thus, 
Table 3. CAT score results in COPD patients

\begin{tabular}{llll}
\hline & $\begin{array}{l}\text { At } \\
\text { discharge }\end{array}$ & $\begin{array}{l}\text { One year after } \\
\text { discharge }\end{array}$ & $\begin{array}{l}p \\
\text { value }\end{array}$ \\
\hline $\begin{array}{l}\text { Intervention group } \\
(n=120)\end{array}$ & $22.94 \pm 2.64$ & $12.87 \pm 1.78^{\mathrm{a}, \mathrm{b}}$ & 0.000 \\
$\begin{array}{l}\text { Control group } \\
(n=120) \\
p \text { value }\end{array}$ & $23.08 \pm 2.68$ & $18.66 \pm 2.72^{\mathrm{a}}$ & 0.011 \\
\hline
\end{tabular}

COPD, chronic obstructive pulmonary disease; CAT, COPD assessment test. ${ }^{\text {a }}$ Compared with the same group at discharge $(p<0.05) .{ }^{b}$ Compared with the control group after 1 year of follow-up $(p<0.05)$.

Table 4. Comparison of patients with $\geq 2$ hospitalizations per year due to an acute exacerbation

\begin{tabular}{lll}
\hline & $\begin{array}{l}\text { Patients with more } \\
\text { than 2 instances } \\
\text { of continuous } \\
\text { hospitalization, } n\end{array}$ & $\begin{array}{l}\text { Years of } \\
\text { continuous } \\
\text { hospitalization }\end{array}$ \\
\hline $\begin{array}{l}\text { Intervention group } \\
(n=120)\end{array}$ & $22(18.33)$ & $2.54 \pm 0.64$ \\
$\begin{array}{l}\text { Control group } \\
(n=120)\end{array}$ & $58(48.33)$ & $3.67 \pm 0.97$ \\
$p$ value & 0.017 & 0.032 \\
\hline
\end{tabular}

Values are presented as numbers (\%) or means \pm SD.

acute exacerbations in COPD patients occur repeatedly in the short term, resulting in continuous hospitalization of patients within a short period of time [15]. This leads to an increased expenditure of the new rural cooperative medical system, and it increases the patient's medical expenses. The operation of the network consulting room has made some fundamental changes in health care [16]. The biggest characteristic is that it ingeniously solves the current problems of medical consultations, high medical costs, and low rates of satisfaction in the management of chronic diseases, due to limitations of manpower, material resources, and financial resources. In the management of patients with COPD under the network consulting room established by the 7LKCOM Internet Hospital, patients can be guided in a timely manner by professional doctors who are familiar with their condition, and they can purchase drugs from home without additional costs. If the condition of these patients worsens and if they require hospitalization, after contacting the doctor, the hospital can prepare the sickbed before the patient arrives.
The Network Consulting Room Improves the Accessibility to Doctors

Doctors input the data of the diagnosis and treatment of patients who receive a diagnosis and treatment in their inpatient department to the network consulting room, which provides individualized health guidance after patients are discharged from the hospital. This allows patients to receive guidance from experts who are familiar with their condition at home, and it avoids the time-consuming disadvantages of the traditional practice of repeated visits to outpatient clinics; it also eliminates travel expenses, registration fees, and fees for repeated examinations.

The Network Consulting Room Enhances the Patient's Disease Control after Discharge

Postdischarge-targeted individualized health education for COPD patients who are hospitalized due to acute exacerbation [17] is an important link that can help patients to manage and control acute exacerbations as soon as possible [18]. This education, aided by short films and articles with pictures that are easy to understand, can teach patients to avoid environments with too much dust or allergies, to eat less spicy food, and to begin cold-resistant exercise in summer [19]. When the remission stage of COPD patients is prolonged and consolidated, the frequency of hospitalization of patients with an acute exacerbation is reduced. The present study revealed that, out of all of the patients, 22 patients (18.33\%) in the intervention group had $\geq 2$ instances of continuous hospitalization due to acute exacerbations within 1 year, while 58 patients $(48.33 \%)$ in the control group had $\geq 2$ instances of continuous hospitalization due to acute exacerbations within 1 year. The number of patients who required continuous hospitalization due to exacerbation was significantly lower in the intervention group than in the control group.

\section{The Network Consulting Room Is Conducive to Management of the Medication of Patients}

COPD patients recuperating at home will inevitably encounter various inducing factors that lead to aggravations [20]. When a patient coughs and encounters a sputum aggravation, he or she can report to their doctor at any time through the network consulting room, and the doctor can adjust the medication in a timely manner according to the symptoms of the patient. When the patient needs supplementation of the drugs, the doctors can prescribe these for them in the network consulting room and the Internet Hospital can then send the drugs to the pa- 
tient's home. The Ministry of Human Resources and Social Development issued a document to promote the application of Internet + online consumption, where patients can pay using their social security card [21], enjoying the same treatment as a reduction of part of the cost of medical insurance for chronic diseases.

\section{Problems and Prospects}

\section{Limitations of This Study}

The number of observed cases was small, the time of observation was short, and the observation indexes were too simple; future studies in this area will need to be further improved in many aspects.

\section{The Problem of the Popularity of Smart Phones}

Some patients in rural areas are not able to use smart phones or do not possess smart phones, and thus communication with doctors is commonly carried out by the patients' sons and daughters. Thus, accuracy and timeliness are often affected.
Network Doctors Who Voluntarily Provide

\section{Telemedicine Should Be Rewarded}

Doctors who use the network consulting room actually undertake the function of a private doctor in a timely, accurate, and effective manner. If these doctors receive an income for this service it increases their enthusiasm.

\section{Research Prospects}

Dissemination of public health knowledge via mobile devices such as mobile phones and the development of applications for chronic disease management based on mobile services can meet the needs of developing times and provide technical support for conveniently obtaining knowledge regarding chronic diseases [22].

\section{Acknowledgement}

We are grateful to all of the individuals who helped us in preparing this paper. This study was funded by the China Medical Board (11-069).

\section{Disclosure Statement}

The authors declare that they have no competing interests.

\section{References}

1 Li YY, Miao YD, Yang F, et al: Progress on the research of health-seeking behaviors of rural patients' with chronic diseases and its influencing factors. Chin Health Serv Manage 2015:617-618.

-2 Ambrosino N, Vagheggini G, Mazzoleni S, et al: Telemedicine in chronic obstructive pulmonary disease. Breathe 2016;12:350356.

3 Guo Ce: The current situation of chronic noncommunicable diseases and community health services in China. Mod Prev Med 2012; 3:607-610.

4 The policy of medical service supported by multi-social forces. Beijing, General Office of the State Council of the People's Republic of China, 2017.

-5 Szawarski P, Hillebrandt D: Doctor won't see you now: changing paradigms in mountain medicine. Postgrad Med 2018;94:182184.

6 Chinese Thoracic Society COPD Group: Strategy for the diagnosis, management and prevention of chronic obstructive pulmonary disease (2013 revised). Am J Respir Crit Care Med 2013;187:255-264.

7 Leng QP, Yang XH: A new method to assess the quality of life of COPD patients. Med Recapitulate 2011;17:3286-3288.

8 Vogelmeier CF, Criner GJ, Martinez FJ, et al: Global strategy for the diagnosis, manage- ment, and prevention of chronic obstructive lung disease 2017 report: GOLD executive summary. Respirology 2017;22:575-601.

9 Niu YD, Liu WJ, Duan L: Empirical study on current readmission in rural areas of 7 counties and districts in China. Chin Health Econ 2016, pp 43-44.

10 Wang SL, Huang JY, Zhou JY: Development of evidence-based transitional care practice for chronic obstructive pulmonary disease. Chin J Nurs 2009;44:423-424.

11 Scalvini S, Bernocchi P, Zanelli E, et al: Maugeri Centre for Telehealth and Telecare: a real-life integrated experience in chronic patients. J Telemed Telecare 2017, DOI: 10.1177/1357633X1771082712.

12 Ni W, Shao X, Cai X, et al: Prophylactic use of macrolide antibiotics for the prevention of chronic obstructive pulmonary disease exacerbation: a meta-analysis. PLoS One 2015; 10:e0121257.

13 Rassouli F, Baty F, Stolz D, et al: Longitudinal change of COPD assessment test (CAT) in a telehealthcare cohort is associated with exacerbation risk. Int J Chron Obstruct Pulmon Dis 2017;12:3103-3109.

14 Orozco-Beltran D, Sánchez-Molla M, Sanchez JJ, et al: Telemedicine in primary care for patients with chronic conditions: the ValCrònic Quasi-Experimental Study. J Med Internet Res 2017;19:e400.
15 Zacho Priess Leere M, Møller Weinreich U: Mortality and readmissions in patients with acute exacerbation of chronic obstructive pulmonary disease treated at a specialised pulmonary ward and general wards. Dan Med J 2014;61:A4938.

16 Yao ZH: Entering the times of mobile health. J Med Inform 2014;35:2-7.

17 Onadeko BO, Khadadah M, Abdella N, et al: Prognostic factors in the management of exacerbation of chronic obstructive pulmonary disease in Kuwait. Med Princ Pract 2005;14:35-40.

18 Wang J, Wang Y, Wei C, et al: Smartphone interventions for long-term health management of chronic diseases: an integrative review. Telemed J E Health 2014;20:570-583.

19 van Eerd EA, van der Meer RM, van Schayck OC, et al: Smoking cessation for people with chronic obstructive pulmonary disease. Cochrane Database Syst Rev 2016;20:CD010744.

20 Han MK, Muellerova H, Curran-Everett D, et al: GOLD 2011 disease severity classification in COPDGene: a prospective cohort study. Lancet Respir Med 2013;1:43-50.

21 Pinnock H, McKinstry B: Digital technology in respiratory diseases: promises, (no) panacea and time for a new paradigm. Chron Respir Dis 2016;13:189-191.

22 Martinez JF, Familiar MS: Composition and deployment of e-health services over wireless sensor networks. Math Comput Model 2011; 53:485-503.
Network Consulting Rooms for the Management of COPD in Rural Areas 